\title{
2012 TriBranch Symposium
}

\section{1-13 JUNE 2012}

Atlantic City Convention Center

Atlantic City, NJ

Total attendance: 498

Total number of exhibitors present: 299 representing 115 companies

Three branches of the American Association for Laboratory Animal Science (AALAS), the New Jersey Branch, the Delaware Valley Branch and the Metro New York Branch, join together each year to sponsor the TriBranch Symposium. The theme of this year's TriBranch Symposium, held 11-13 June in Atlantic City, NJ, was R5: Reduction, Refinement, Replacement, Respect and Responsibility. Presentations and workshops centered around the traditional principles of the '3Rs' (reduction, refinement and replacement) that guide the care and use of animals in research, while extending these principles to include respectful and responsible treatment of animals.The symposium offered 11 Workshops and Special Topic Discussions attended by 78 individuals. Presentation topics included enrichment strategies, health monitoring, behavioral training and reducing stress during procedures. Sessions on enrichment and behavior largely focused on nonhuman primate populations. A Webinar was also offered for specific lectures to offsite audiences, including local students in the area.

The symposium featured Special Presentations that covered important topics. On Tuesday afternoon, representatives from the Office of Laboratory Animal Welfare (OLAW, NIH), the US Department of Agriculture (USDA, APHIS, AC) and the Association for the Assessment and Accreditation of Laboratory Animal Care (AAALAC) International presented updates from their respective agencies. Eileen Morgan pointed out that OLAW has now adopted the eighth edition of the Guide for the Care and Use of Laboratory Animals. Michael J. Smith identified the most common citations issued by USDA as relating to a facility's semi-annual inspection report. Richard B. Huneke noted that since AAALAC International began implementing the eighth edition of the Guide, several topics that are affected by the new recommendations have been identified, including cage space allotments (e.g., in trio breeding).

On Wednesday morning, security specialist John Sancenito discussed security issues for research institutions related to animal rights extremism. Mainstream animal rights groups have the most public support and funding and typically engage in law-abiding forms of protest, whereas underground extremist groups are most likely to perform criminal acts against research institutions and personnel, such as vandalism and animal liberation. Although such criminal activity is decreasing worldwide, Sancenito suggested that

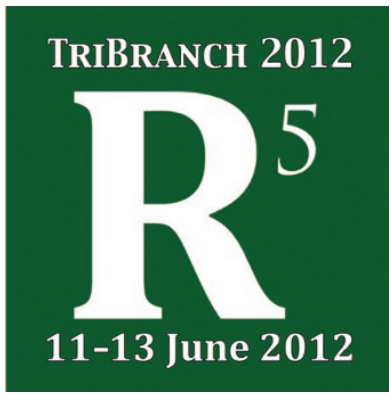

institutions can increase their security against such attacks through close monitoring of public exposure through websites, including employees' social networking accounts; more thorough security policies and procedures; and increased awareness of the risk of infiltration among staff.

Paul McKellips, author of Uncaged and Vice President of the Foundation for Biomedical Research (FBR), closed the symposium with a presentation on changing public perception about biomedical research. McKellips argued that effective communication should be the first approach to countering the attacks of animal activist groups to win the hearts and minds of the public. The public should be informed that mainstream animal rights groups mislead them about animal research by using lies, intimidation, violence and fear in their campaigns. Furthermore, while the official position of most research institutions has been to remain silent in the face of attacks, McKellips' work with FBR has shown that informing the public about the benefits of research using animals is an effective way of winning their support. FBR launched the Research Saves project in 2009, which emphasizes the medical benefits of biomedical research, puts a human face on the scientists who conduct this research and uses emotion-based approaches such as showing the human patients and even animals that have benefited from such research. After the launch of this initiative, illegal incidents associated with animal rights activism have plummeted, while public support for research using animals has risen from $49.9 \%$ in 2009 to $65.7 \%$ in 2012 .

Thirty-five posters were presented at the symposium. First-place winners included "Essential Venipuncture Techniques in Rodents" by Kimberly Wasko, Drexel University College of Medicine (institutional category), and "Vacant Cage Verification Device" by Guy Allen, Bristol-Myers Squibb (corporate category). "Natural Environmental Enrichment Increases the Scientific Viability of Mouse Models" by Casey Acklin, College of the Atlantic, received the award for best poster on the topic of enrichment, and the host branch (NJ) poster award went to "Implementation of a Commercial Electronic Veterinary (e-vet) Records System in a GLP Environment" by John Arzadon, Novartis Institutes for BioMedical Research. 